\title{
Additively Manufactured Commercial Co-Cr Dental Alloys: Comparison of Microstructure and Mechanical Properties
}

\author{
Dalibor Viderščak ${ }^{1, *(1)}$, Zdravko Schauperl ${ }^{1}$, Sanja Šolić ${ }^{2}$, Amir Ćatić ${ }^{3}(0)$, Matjaž Godec ${ }^{4}$, Aleksandra Kocijan ${ }^{4}$, \\ Irena Paulin ${ }^{4}$ and Črtomir Donik ${ }^{4}$ (1) \\ 1 Faculty of Mechanical Engineering and Naval Architecture, University of Zagreb, Ivana Lučića 5, \\ 10000 Zagreb, Croatia; zdravko.schauperl@fsb.hr \\ 2 Department of Mechanical Engineering, University North, Jurja Križanića 31b, 42000 Varaždin, Croatia; \\ ssolic@unin.hr \\ 3 School of Dental Medicine, University of Zagreb, Gundulićeva 5, 10000 Zagreb, Croatia; catic@sfzg.hr \\ 4 Institute of Metals and Technology, Lepi pot 11, 1000 Ljubljana, Slovenia; matjaz.godec@imt.si (M.G.); \\ Aleksandra.kocijan@imt.si (A.K.); irena.paulin@imt.si (I.P.); crtomir.donik@imt.si (Č.D.) \\ * Correspondence: dalibor.viderscak@fsb.hr
}

check for

updates

Citation: Viderščak, D.; Schauperl, Z.; Šolić, S.; Ćatić, A.; Godec, M.; Kocijan, A.; Paulin, I.; Donik, Č. Additively Manufactured Commercial Co-Cr Dental Alloys: Comparison of Microstructure and Mechanical Properties. Materials 2021 14, 7350. https://doi.org/10.3390/ ma14237350

Academic Editor: George Eliades

Received: 4 November 2021

Accepted: 27 November 2021

Published: 30 November 2021

Publisher's Note: MDPI stays neutral with regard to jurisdictional claims in published maps and institutional affiliations.

Copyright: (c) 2021 by the authors. Licensee MDPI, Basel, Switzerland. This article is an open access article distributed under the terms and conditions of the Creative Commons Attribution (CC BY) license (https:// creativecommons.org/licenses/by/ $4.0 /)$.
Abstract: Laser-powder bed fusion (LPBF) is one of the preferred techniques for producing Co$\mathrm{Cr}$ metal structures for dental prosthodontic appliances. However, there is generally insufficient information about material properties related to the production process and parameters. This study was conducted on samples produced from three different commercially available Co-Cr dental alloys produced on three different LPBF machines. Identically prepared samples were used for tensile, threepoint bending, and toughness tests. Light microscopy (LM), scanning electron microscopy (SEM), and electron backscatter diffraction (EBSD) analyses of microstructure were performed after testing. Differences were observed in microstructures, which reflected statistically significant differences in mechanical properties (one-way analysis of variance (ANOVA) and Scheffé post hoc test $(\alpha=0.05)$ ). The material produced on the 3D Systems DMP Dental 100 had 24 times greater elongation $\varepsilon$ than the material produced on the Sysma MySint 100 device and the EOS M100 machine. On the other hand, the material produced on the EOS M100 had significantly higher hardness (HV0.2) than the other two produced materials. However, the microstructure of the Sysma specimens with its morphology deviates considerably from the studied group. LPBF-prepared $\mathrm{Co}-\mathrm{Cr}$ dental alloys demonstrated significant differences in their microstructures and, consequently, mechanical properties.

Keywords: Co-Cr dental alloys; LPBF; microstructure; mechanical properties; SEM; EBSD

\section{Introduction}

Additively manufactured (AM) Co-Cr-based alloys are used for metallic structures of dental appliances and generally for biomedical purposes. Due to their excellent mechanical properties with a combination of high wear, corrosion resistance, and biocompatibility, $\mathrm{Co}-\mathrm{Cr}$ alloys are one of the standard materials in biomedical applications. In addition, $\mathrm{Co}-\mathrm{Cr}$ alloys for dental appliances demonstrate optimal manufacturing, biomedical, and economic characteristics [1,2].

Laser-powder bed fusion (LPBF) machines for Co-Cr dental alloys are widely available on the market. All manufacturers declare that products produced on their devices meet all professional standards (primarily EN ISO 22674:2016) and are comparable or better to products made by conventional production processing (casting) [3]. However, just a few studies are available that investigate the impact of the production parameters and machine set-up for AM production on the quality and mechanical characteristics of dental metal-based constructions for fixed partial dentures (FPDs) [4,5].

Co-Cr dental alloys are produced from LPBF techniques such as selective laser melting (SLM), which allow us to overcome the imperfections of traditional manufacturing processes (casting and milling). With SLM, layer by layer of metal powder is melted into a 3D 
object with a directed laser beam. The main advantage of the SLM manufacturing process over traditional casting is the possibility of producing complex personalized objects much faster with similar or better properties compared to conventional manufacturing [5-7]. Digital technologies have been in use for more than three decades in dental medicine, with the first CEREC machine utilizing CAD/CAM principles having been on the market since 1986. However, only in the last decade, the exponential development of digital technologies, specifically AM and intraoral 3D scanning devices, has significantly increased their impact and use in everyday clinical practice [6-9]. This increase followed technological advances in intraoral scanners' precision, handling, ease of use, compatibility, and interconnectivity with commonly used dental design software such as ExoCAD (ExoCAD Int., San Jose, CA, USA), Trios 3Shape (Trios, Denmark), and InLine (Dentsply-Sirona Co., Charlotte, NC, USA). Clinical implementation of new technologies calls for modifications and optimizations of clinical and technical protocols [10,11]. Within technical protocols are also those dealing with the production of dental prosthodontic appliances regarding input material quality and characteristics, input material handling protocols, production specifics, and output quality control with final standardized products regarding mechanical and biochemical properties, biopotentials, cytological dynamics, and forensic aspects [12,13]. However, those technical production protocols are still undefined and are by no means standardized, resulting in a vast array of products with undefined characteristics. Such a situation on the dental market leaves both dentists and patients unaware of the material quality or the quality of the prosthodontic appliances placed in function, which can have a significant impact on clinical performance and durability as well as potential warranty issues [14-19].

Dental and generally biomedical Co-Cr alloys consist of 51.8-65.8 wt \% of Co; $23.7-$ $30.0 \mathrm{wt} \%$ of $\mathrm{Cr} ; 4.6-5.6 \mathrm{wt} \%$ of Mo; $4.9-5.9 \mathrm{wt} \% \mathrm{~W}$; and $<1 \mathrm{wt} \%$ of Mn, Si, and Fe [12]. The mechanical properties of $\mathrm{Co}-\mathrm{Cr}$ dental alloys primarily depend on the chemical composition, microstructure, and manufacturing process. Pure Co exists in two allotropic modifications: at temperatures below $417^{\circ} \mathrm{C}$ in the HCP structure, while an FCC structure is stable above this temperature. The microstructure of dental alloys consists of the $\gamma$ phase (FCC lattice) with carbides and the $\varepsilon$ phase (HCP lattice). The $\gamma$ phase affects mechanical properties (ductility) while the $\varepsilon$ phase affects tribo-corrosion properties (wear and corrosion resistance) [1,20-24]. Properties of $\mathrm{Co}-\mathrm{Cr}$ dental alloys greatly depend on the $\gamma-\varepsilon$ ratio (FCC-HCP ratio) and other inclusions, predominantly carbides, in the microstructure (type, distribution, and quantity of the carbides) [5,25-27].

High heat and cooling rates are characteristics of the SLM process. High heat and cooling rates lead to phase transformations and result in microstructural changes in the $\gamma-\varepsilon$ ratio, and, consequently, in the material properties (mechanical, wear, and corrosion) of the final products $[15,20]$. SLM main process parameters such as laser power, scanning speed, layer thickness, hatching distance, the temperature of the building platform, and scanning strategy lead to differences in the microstructure of the produced parts and modifications of the mechanical properties [3,14,26]. Recent studies reported that $\mathrm{Co}-\mathrm{Cr}$ dental alloys produced by the SLM process have a higher corrosion resistance [26] and higher yield and tensile strengths compared to the cast alloys. In the SLM Co-Cr dental alloys, mechanical anisotropy was detected due to changes in the obtained microstructure [16]. The SLM-produced Co-Cr alloys met the properties according to the ISO 22674:2016 (type 5 criteria) such as UTS, yield strength, and elongation and were higher than manufactured by casting $[1-3,27-31]$. Therefore, optimizing the main SLM production parameters is essential for producing $\mathrm{Co}-\mathrm{Cr}$ dental alloys with the necessary characteristics for dental appliances [3,26].

The main objective of this study is to compare the mechanical properties of additively produced commercial $\mathrm{Co}-\mathrm{Cr}$ alloys for dental appliances on three different machines with three types of metal powders where manufacturers guarantee compliance with the requirements according to EN ISO 22674:2016. Three types of samples were additively manufactured (LPBF) for testing mechanical properties and analysis microstructures using 
light microscopy (LM), scanning electron microscopy (SEM), electronic backscattering techniques (EBSD), and chemical composition analysis to try to correlate these obtained mechanical properties with the microstructure. Based on all these results, we propose the standardization of LPBF procedures for dental use.

\section{Materials and Methods}

Three sets of three specimens were produced using (a) Sysma MySint100 (BEGO Medical GmbH, Bremen, Germany), (b) EOS M100 (EOS GmbH, Krailling, Germany), and (c) 3D Systems DMP Dental 100 (3D Systems, Rock Hill, SC, USA). All specimens were produced and heat-treated for stabilization according to the producer-recommended parameters. The shape and dimensions of the printed specimens are shown in Figure 1.
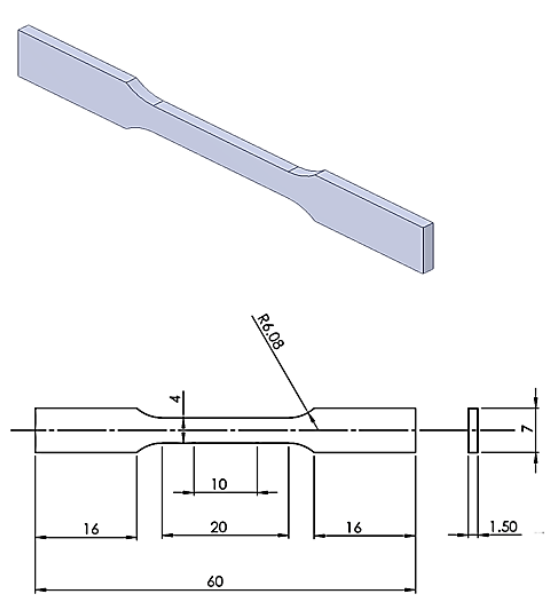

(a)

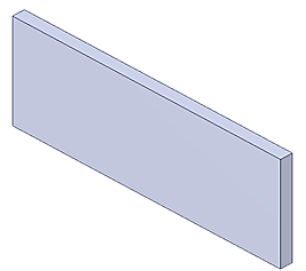

34

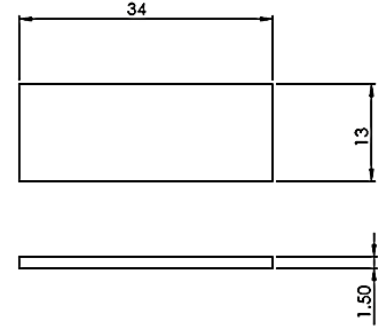

(b)
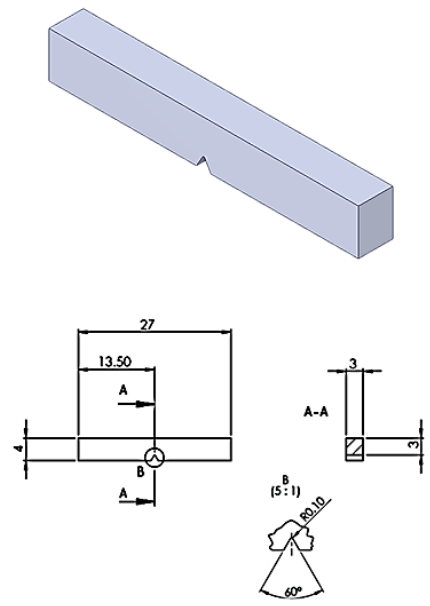

(c)

Figure 1. Schemes of the produced specimens: (a) static tensile test, (b) three-point bending, (c) impact toughness (V-notch).

We conducted tests for static tensile strength (tensile strength $R_{m}, \mathrm{MPa}$, and elongation $\varepsilon$, \%; Beta 50-5, Messphysik, Austria), three-point bending (flexural strength $R_{f M}, \mathrm{MPa}$; Inspekt Table Blue 20 kN, Hegewald \& Peschke Meß- und Prüftechnik GmbH, Germany), Charpy impact toughness test (impact toughness, CVN; Charpy impact machine, Karl Frank GmbH, Weinheim-Birkenau, Germany), and microhardness (HV0.2; Wilson-Wolpert Tukon 2100B; Instron, Norwood, MA, USA). The microstructural characterization of the specimens was performed for impact toughness in two vertical cross-sections. For the microstructural analysis, specimens were prepared with the standard metallographic procedure followed by electrochemical etching with $10 \mathrm{vol} \%$ of oxalic acid at $12 \mathrm{~V}$ for three minutes. The microstructure was analyzed using the light microscope OLYMPUS GX51F-5 with the attached Olympus DP-25 CCD camera. A field-emission scanning electron microscope (FE-SEM), ZEISS CrossBeam 550 FIBSEM (Oberkochen, Germany), equipped with an EDAX Hikari Super EBSD camera, was used for the detailed microstructural characterization with EDAX TEAM software. Secondary electron imaging (SEI) and electron backscatter diffraction (EBSD) was carried out on FE-SEM. SE images and EDS analyses were performed using $15 \mathrm{kV}$ accelerating voltage and 2.0-5.0 nA probe current, while EBSD measurements were carried out on $70^{\circ}$ tilted samples and $7.0 \mathrm{nA}$ probe current for phase composition. The EBSD characterization was performed on randomly selected field of appx. $500 \times 400 \mu \mathrm{m}$. Chemical composition was performed on ICP OES, Agilent 5800 (Santa Clara, CA, USA), and carbon content on ELTRA CS 800 (Eltra GmbH, Haan, Germany).

The obtained values of mechanical properties were analyzed using SPSS Version 20 (Illinois, USA). The values between different groups were evaluated with a one-way analysis of variance (ANOVA) and Scheffé post hoc test $(\alpha=0.05)$. 
Table 1 shows the type and the composition of Co-Cr powder used for each device, as specified by the manufacturer.

Table 1. SLM machine, Co-Cr powder type, and chemical composition (wt \%) according to manufacturers.

\begin{tabular}{|c|c|c|}
\hline Machine & Co-Cr Powder Type & $\begin{array}{l}\text { Powder Chemical Composition } \\
\text { (wt \%) }\end{array}$ \\
\hline Sysma MySint100 & Wirobond C+ & $\begin{array}{c}\text { Co (63.9), Cr (24.7), W (5.4), Mo } \\
\text { (5.0), Si }(<1.0)\end{array}$ \\
\hline EOS M100 & Cobalt Chrome SP2 & $\begin{array}{c}\text { Co (63.8), Cr (24.7), Mo (5.1), W } \\
\text { (5.4), Si (1), other }(<1.0)\end{array}$ \\
\hline $\begin{array}{l}\text { 3D Systems DMP Dental } \\
100\end{array}$ & Laser Form CoCr (B) & $\begin{array}{c}\text { Co (bal.), Cr (28.0-30.0), Mo } \\
(5.0-6.0), \mathrm{Si}(0.0-1.0), \mathrm{Mn}(0.0-1.0), \\
\text { Fe }(0.0-0.5), \mathrm{C}(0.0-0.02)\end{array}$ \\
\hline
\end{tabular}

\section{Results}

The results of the tested mechanical properties of all specimens are presented in Table 2. The values in the table represent the mean value from three measurements $(n=3$ per group) and their standard deviations. The mean values of HV0.2 were measurement $(n=10)$ in two mutually perpendicular directions of Co-Cr specimens.

Table 2. Mean values and standard deviations of conducted mechanical properties.

\begin{tabular}{|c|c|c|c|c|c|}
\hline $\begin{array}{c}\text { Type of } \\
\text { Mechanical Test }\end{array}$ & & anical Property & Sysma MySint 100 & EOS M100 & $\begin{array}{l}\text { 3D Systems DMP } \\
\text { Dental } 100\end{array}$ \\
\hline \multirow{3}{*}{ Static tensile test } & & ngation $\varepsilon / \%$ & $0.33 \pm 0.1^{\mathrm{a}}$ & $4.90 \pm 1.1^{b}$ & $8.1 \pm 1.5^{\mathrm{c}}$ \\
\hline & Ten & trength $R_{m} / \mathrm{MPa}$ & $1112 \pm 123.7^{a}$ & $1370 \pm 13.6^{b}$ & $1016 \pm 61.7^{a}$ \\
\hline & Yiel & ength $R_{p 0.2} / \mathrm{MPa}$ & $834 \pm 62^{a}$ & $1061 \pm 21^{b}$ & $822 \pm 43^{a}$ \\
\hline $\begin{array}{c}\text { 3-point bending } \\
\text { test }\end{array}$ & & $R_{f M} / \mathrm{MPa}$ & $2059 \pm 251.9^{a}$ & $2527 \pm 92.7^{b}$ & $2548 \pm 54.3^{b}$ \\
\hline $\begin{array}{l}\text { (Impact) } \\
\text { Toughness }\end{array}$ & & $\mathrm{CVN} / \mathrm{J}$ & $0.26 \pm 0.02^{a}$ & $0.27 \pm 0.03^{a}$ & $0.61 \pm 0.01^{b}$ \\
\hline \multirow{2}{*}{ Microhardness } & \multirow{2}{*}{ HV0.2 } & Cross-section & $568 \pm 27^{a}$ & $770 \pm 80^{b}$ & $513 \pm 12^{a}$ \\
\hline & & Longitudinal-section & $554 \pm 8^{a}$ & $719 \pm 59^{b}$ & $587 \pm 44^{\mathrm{a}}$ \\
\hline
\end{tabular}

Different superscript letter in a row indicates statistically significant difference $(p<0.05)$.

The obtained chemical composition of specimens is given in Table 3.

Table 3. Chemical composition of specimens (wt \%).

\begin{tabular}{cc}
\hline Machine & Chemical Composition (wt \%) \\
\hline Sysma MySint100 & Co (bal.), Cr (24.6 \pm 0.2$), \mathrm{W}(5.7 \pm 0.08), \mathrm{Mo}(5.3 \pm 0.08), \mathrm{Fe}$ \\
$(0.19 \pm 0.01), \mathrm{Mn}(0.05 \pm 0.002), \mathrm{C}(0.008 \pm 0.001)$
\end{tabular}

The chemical composition from Table 3 matches the declared chemical composition of the manufacturers. For example, the chemical composition of $\mathrm{Co}-\mathrm{Cr}$ powders Wirobond C+ (Sysma MySint100) and Cobalt Chrome SP2 (EOS M100) is similar. In contrast, CoCr powder Laser Form CoCr (B) (3D System DMP Dental 100) does not have a similar 
amount of W $(0.19 \mathrm{wt} \%)$. Crucial is C content due to its effect on the mechanical properties (carbides are formed) [5].

The addition of molybdenum (Mo) and wolfram $(\mathrm{W})$ leads to solid solution strengthening and the formation of MoC- and WC-type carbides and $\mathrm{Co}_{3} \mathrm{~W}$ and $\mathrm{Co}_{3} \mathrm{Mo}$ intermetallic phase (HCP- $\varepsilon$ phase). The carbon content (even in a small range) greatly influences mechanical properties (the volume of $\gamma$ phase increased-higher elongation $\varepsilon$ ). Co-Cr dental alloys consist mainly of $\gamma$ phase and carbides of the $(\mathrm{Cr}, \mathrm{Fe}, \mathrm{W}, \mathrm{Mo})_{23} \mathrm{C}_{6}$ (higher $R p_{0.2}, R_{m}$, and hardness) $[5,32,33]$. The obtained mechanical properties depend on the $\gamma-\varepsilon$ (FCC-HCP) ratio $[26,31]$.

\section{Microstructure Analysis}

The microstructure of the specimens was analyzed using a light microscope. Characteristic microstructures under the same magnification are presented in Figure 2. The microstructure of the specimens built on the Sysma MySint100 device (Figure 2a) [12] indicates morphology of the microstructure, which can be the result of low values of Laser Energy Density (LED) $\left(\mathrm{J} \mathrm{mm}^{-3}\right)$ used during the SLM process according to [16]. Low LED values can also lead to large internal porosity and a lack of fusion between the layers [12]. The observed porosity is presented in Figure 3 . Figure $2 b, c$ and Figure $3 b, c$ present continuous microstructure of regular morphology, which is characteristic for medium and high values of LED [16].
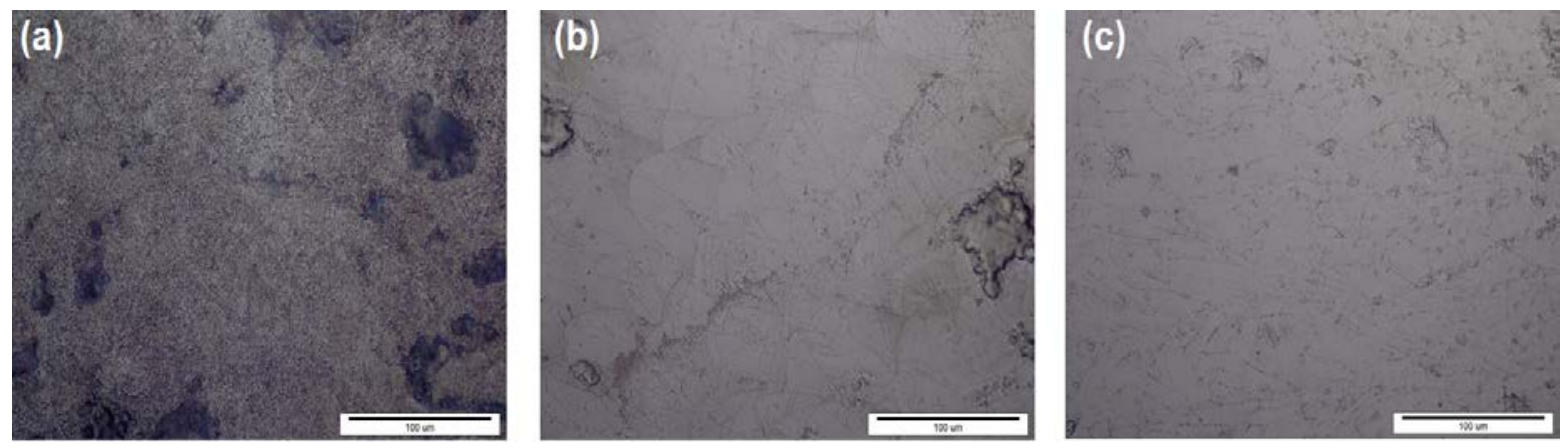

Figure 2. Microstructure, LM, etched: (a) Sysma MySint 100, (b) EOS M100, (c) 3D Systems DMP Dental 100.
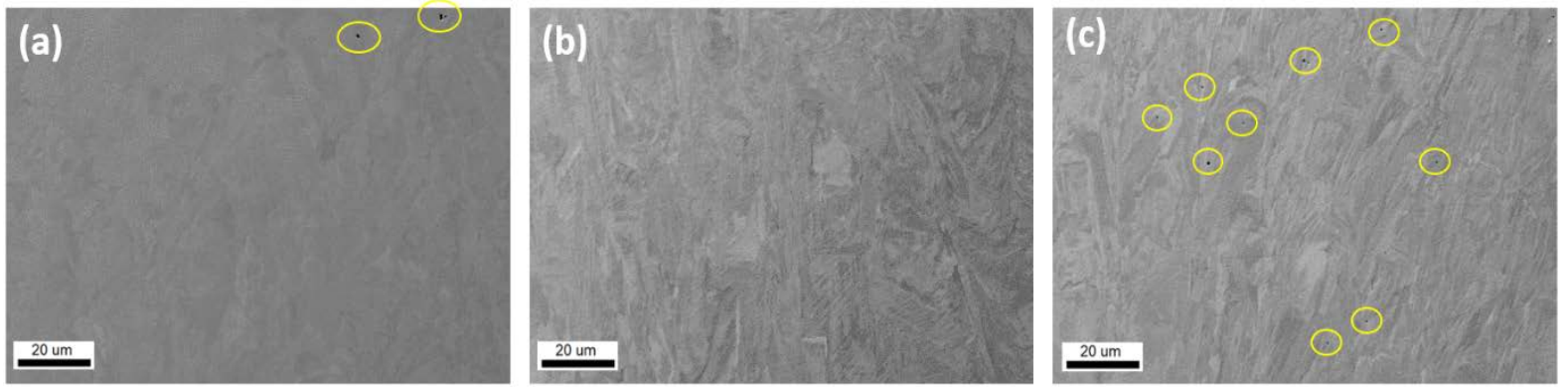

Figure 3. Microstructure of specimens: (a) Sysma MySint100, (b) EOS M100, (c) 3D Systems DMP Dental 100. Yellow circles mark porosities.

The SEM analysis shows mostly uniformly annealed microstructure of the specimens with the characteristic morphology for additive manufacturing technologies. Studies of the specimens also show some local porosity (yellow circles in Figure 3). Regardless of the selected areas, no visible differences were observed.

The EBSD analyses on prepared samples show the differences in the microstructure. EBSD inversed pole figures in the Z-direction (IPF Z) micrographs and phase maps with HCP and FCC phase amounts are presented in Figure 4. The microstructure of the observed specimens presents typical AM-prepared material with melt pool shapes and cellular 
structures in different directions. AM processes show that an equiaxed grain shape is formed at a high solidification rate and a low-temperature gradient due to powder thermal conductivity. On the other hand, a planar grain structure is formed with a high-temperature gradient and low solidification, and in between, a columnar grain shape is created [34]. The main differences of the studied Co-Cr samples are in the amount of HCP phase in the prepared sample: $15 \%$ in Sysma, $6.1 \%$ in EOS, and $1.3 \%$ in 3D Systems.
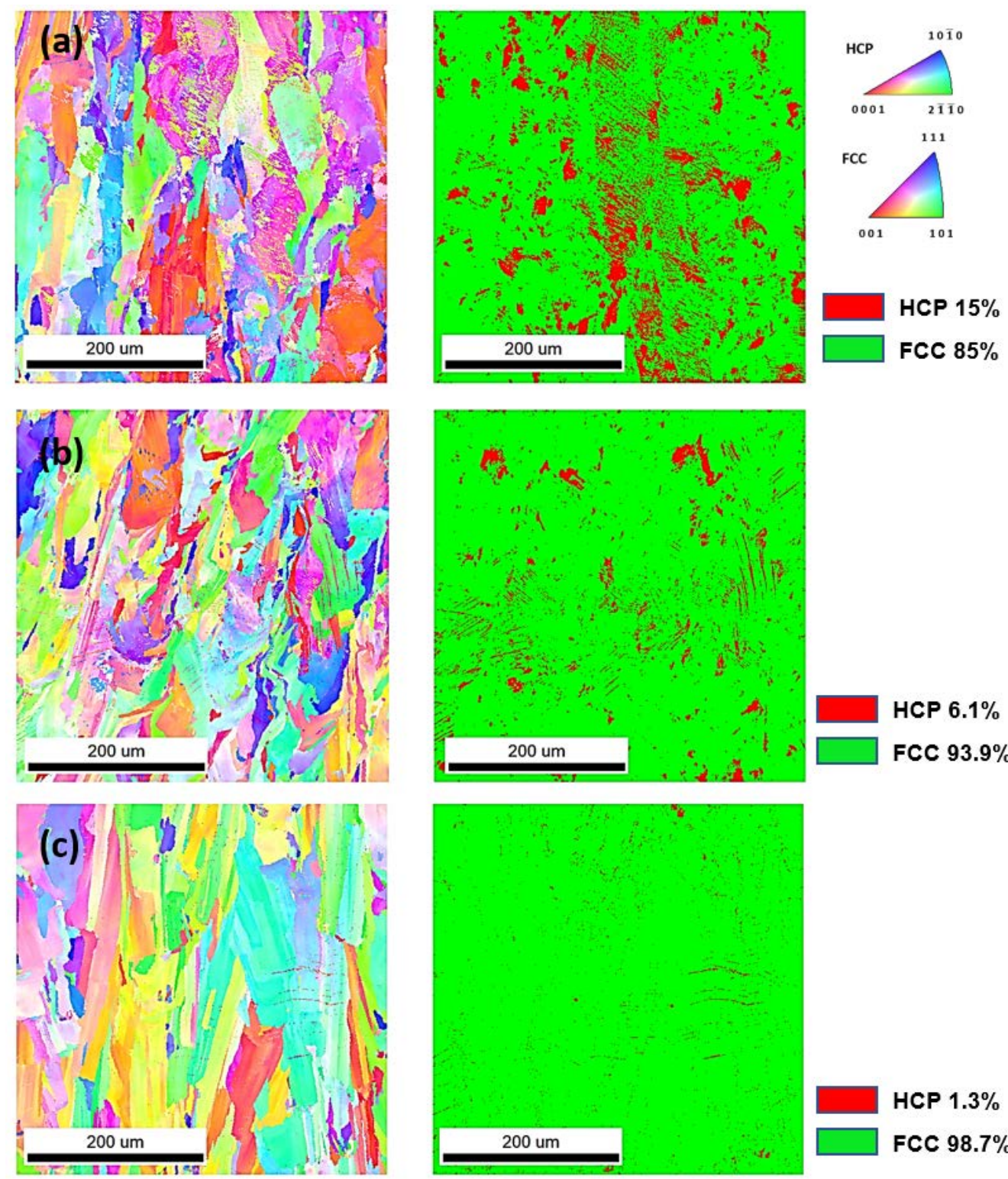

HCP $6.1 \%$

FCC $93.9 \%$

Figure 4. EBSD images of IPF $\mathrm{Z}$ with lagend and phase map with the amount of each phase of (a) Sysma MySint100, (b) EOS M100, (c) 3D Systems DMP Dental 100.

\section{Discussion}

The present study results show significant differences in the values of the mechanical properties of the specimens, depending on the used device shown in Table 2 ( $p$ values $<0.05$ were considered statistically significant).

The most significant deviations are present in elongation $\varepsilon$, where specimens made on the 3D Systems DMP Dental 100 have 24 times greater elongation $\varepsilon(0.33 \pm 0.1<8.1 \pm 1.5$, $p<0.05)$ than specimens made on the Sysma MySint100 device.

The tensile strength $R_{m}$ of the specimens produced on EOS M100 has a statistically higher value $(p<0.05)$ from other devices. In contrast, the lowest bending strength is 
measured on the Sysma MySint100 specimens $(p<0.05)$. Specimens from this device also have the highest standard deviations of $R_{m}$ and $R_{f M}$ values.

No differences in microhardness (HV0.2) were measured between the cross and longitudinal sections of the specimens made on the same machines. However, the microhardness of specimens made on the EOS M100 machine is significantly higher than the two other groups of specimens $(p<0.05)$.

Analysis of the microstructures showed that the microstructure of the Sysma MySint100 specimens differ slightly from the other two groups of specimens in its morphology. The microstructure of the other two specimens has a fine-grain microstructure with clearly visible boundaries between the grains. Thus, they have typical morphology for the material obtained by laser melting with melt pools overlapping [23]. The carbide precipitates were not found along the grain boundaries either in the grains.

Based on the literature $[3,30,31,35-37]$, the mean values and standard deviations of the mechanical properties of milled (CNC), cast, and SLM-produced Co-Cr alloys, are presented in Table 4, along with EN ISO 22674 criteria.

Table 4. Mean values and standard deviations of mechanical properties of milled (CNC), cast, and SLM-produced Co-Cr alloys from the literature, and EN ISO 22674:2016.

\begin{tabular}{|c|c|c|c|c|}
\hline Property & Milled (CNC) & Cast & SLM & EN ISO 22674:2016 \\
\hline $\begin{array}{c}\text { Tensile Strength } \\
R_{m} / \mathrm{MPa}\end{array}$ & $\begin{array}{l}638 \pm 25[31] \\
1069 \pm 10[3]\end{array}$ & $\begin{array}{c}450[30] \\
520 \pm 30[31] \\
783 \pm 32[3]\end{array}$ & $\begin{array}{c}1072 \pm 18[31] \\
1158 \pm 10[3] \\
1200 \pm 24[36]\end{array}$ & - \\
\hline $\begin{array}{l}\text { Yield Strength } \\
R_{p 0.2} / \mathrm{MPa}\end{array}$ & $\begin{array}{c}495 \pm 20[31] \\
672 \pm 4[3]\end{array}$ & $\begin{array}{c}581 \pm 16[3] \\
655[37] \\
658 \pm 44[31]\end{array}$ & $\begin{array}{c}783 \pm 15[3] \\
790 \pm 11[31] \\
870 \pm 26[35]\end{array}$ & $\geq 500$ \\
\hline Elongation $\varepsilon / \%$ & $\begin{array}{c}10 \pm 1[3] \\
11.1 \pm 1[31]\end{array}$ & $\begin{array}{c}8 \text { [37] } \\
8 \pm 0.4[31] \\
12 \pm 2[3]\end{array}$ & $\begin{array}{c}8.7 \pm 1.06[36] \\
12.7 \pm 1.9[31] \\
13 \pm 1[3]\end{array}$ & $\geq 2$ \\
\hline $\begin{array}{c}\text { 3-point bending test } \\
R_{f M} / \mathrm{MPa}\end{array}$ & - & $1136 \pm 1[30]$ & $2501 \pm 9.7[30]$ & - \\
\hline Hardness HV10 & $\begin{array}{c}264 \pm 11[35] \\
325 \pm 18[31] \\
353 \pm 6[3]\end{array}$ & $\begin{array}{c}270 \pm 16[35] \\
303 \pm 15[3] \\
324 \pm 27[31]\end{array}$ & $\begin{array}{c}399 \pm 24[3] \\
466 \pm 13[35] \\
475 \pm 10[31]\end{array}$ & - \\
\hline
\end{tabular}

Comparing the measured values of mechanical properties in Table 2 with the mean values from the literature in Table 4, depending on the production technology, it can be concluded that the SLM technology can produce Co-Cr dental alloys that meet the EN ISO 22674:2016 type 5 criteria $\left(R_{p 0.2} \geq 500 \mathrm{MPa}\right.$ and $\left.\varepsilon \geq 2 \%\right)$. They also have better mechanical properties than $\mathrm{Co}-\mathrm{Cr}$ alloys produced by conventional production processes (milled (CNC) and cast). However, the mean value of elongation $\varepsilon(0.33 \pm 0.1)$ on Sysma Mysint 100 does not meet EN ISO 22674:2016 standards and is not comparable with mean values obtained with conventional production procedures (Table 4). On the other hand, other values of all mechanical properties of the materials produced on three different machines from Table 2 are comparable to the obtained mechanical properties in [3,30,31,35-37] (Table 4). Therefore, comparing the mechanical properties of specimens prepared by different machines, the $3 \mathrm{D}$ Systems DMP Dental 100 can be compared to the values presented in Table 4. At the same time, EOS M100 has an elongation $\varepsilon$ about $50 \%$ lower $(4.90 \pm 1.1<8 \pm 1.5, p<0.05)$ but meets EN ISO 22674:2016. In contrast, specimens obtained with Sysma MySint100 did not meet the elongation value $\varepsilon(0.33 \pm 0.1)$ according to EN ISO 22674:2016.

According to the Co-Cr binary phase diagram, chromium stabilizes the HCP cobalt in conventionally produced material. Nevertheless, in our study, the phase composition of Sysma MySint 100 and EOS M100 produced materials with similar Cr content displays the different amounts of HCP structure. On the other hand, the 3D Systems DMP Dental 
100 with the highest amount of $\mathrm{Cr}$ contain almost no HCP structure. This phenomenon can be explained by non-equilibrium (rapid) solidification in AM processes. Therefore, it is necessary to perform further microstructural analyzes and mechanical tests of AMproduced samples to determine the mechanisms of microstructural formation.

\section{Conclusions}

From the obtained results, the following conclusions can be drawn:

- The mechanical properties of Co-Cr specimens made on Sysma MySint 100, EOS M100, and 3D Systems DMP Dental 100 are comparable or even better than the mechanical properties of $\mathrm{Co}-\mathrm{Cr}$ specimens produced by the conventional routes, which are casting and milling $(\mathrm{CNC})$ technologies (except for elongation $\varepsilon$, on Sysma MySint 100 and EOS M100).

- The results of the current study demonstrate that the tested specimens meet at least the type 5 criteria in mechanical properties according to the EN ISO 22674:2016 $\left(\mathrm{R}_{p 0.2}\right.$ $\geq 500 \mathrm{MPa}$ and $\varepsilon \geq 2 \%$ ), except the Sysma Mysint100 specimens for elongation $\varepsilon$.

- The highest elongation $\varepsilon(8.1 \pm 1.5 \%)$, flexural strength $R_{f M}(2548 \pm 54.3 \mathrm{MPa})$, and toughness CVN $(0.61 \pm 0.01 \mathrm{~J})$ have specimens produced by 3D Systems DMP Dental 100 (highest content of $\mathrm{Cr}(29.1 \pm 0.2 \mathrm{wt} \%)$ and $\mathrm{C}(0.015 \pm 0.002 \mathrm{wt} \%)$ without higher content of $\mathrm{W}(0.19 \pm 0.01 \mathrm{wt} \%)$ leads to formatting more $\mathrm{Cr}_{23} \mathrm{C}_{6}$ carbides, which determine the higher proportion of $\gamma$ phase (FCC) and better mechanical properties).

- $\quad$ The highest tensile strength $R_{m}(1370 \pm 13.6 \mathrm{MPa})$, yield strength $R_{p 0.2}(1370 \pm 13.6$ $\mathrm{Mpa})$, and the microhardness HV0.2 in cross-section $(770 \pm 80)$ and longitudinalsection $(719 \pm 59)$ have the specimens made on the EOS M100 (the higher HCP $(\varepsilon$ phase) amount contributes to higher hardness and mechanical properties such as $R_{m}$ and $R_{p 0.2}$ but decreases elongation $\varepsilon-\mathrm{W}(5.6 \pm 0.09 \mathrm{wt} \%)$ and $\mathrm{Mo}(5.3 \pm 0.08 \mathrm{wt} \%)$, leading to formatting $\mathrm{Co}_{3} \mathrm{~W}$ and $\mathrm{Co}_{3} \mathrm{Mo}$ intermetallic $\mathrm{HCP}$ phase).

- Microstructural analyses show the highest HCP amount of $15 \%$ ( $\varepsilon$ phase) in Sysma MySint100 specimens (higher content of C $(0.008 \pm 0.001 \mathrm{wt} \%)$ leads to formatting $\mathrm{Cr}_{7} \mathrm{C}_{3}$ ( $\varepsilon$ phase), MoC, and WC carbides, which leads to decreasing mechanical properties (especially elongation $\varepsilon$ ), which causes lower mechanical properties compared to the other two AM-produced materials).

From the obtained results' deviation among commercial $\mathrm{Co}-\mathrm{Cr}$ dental alloys producers, the standardization of process parameters and feedstock powders for $\mathrm{Co}-\mathrm{Cr}$ dental prosthodontic appliances is essential.

Author Contributions: Conceptualization, S.Š. and Z.S.; methodology, D.V., M.G., A.K. and A.Ć.; software, I.P. and Č.D.; validation, S.Š., M.G. and Č.D.; formal analysis, D.V. and Č.D.; investigation, D.V., Z.S., A.K. and A.C.; writing—original draft preparation, D.V., S.Š. and Č.D.; writing—review and editing, S.Š., A.Ć. and Č.D.; supervision, S.Š. and I.P.; funding acquisition, A.Ć. and M.G. All authors have read and agreed to the published version of the manuscript.

Funding: This research was funded by bilateral Croatian-Slovenian project "The impact of 3D printing parameters on structure and properties $\mathrm{Co}-\mathrm{Cr}$ products for stomatological prosthetics-2019500"; project "KK.01.1.1.07.0013-Innovative Ti-Mg dental implants for the world market" and by the University North project UNIN-TEH-20-1-15.

Institutional Review Board Statement: Not applicable.

Informed Consent Statement: Not applicable.

Data Availability Statement: The data presented in this study are available on request from the corresponding author.

Acknowledgments: This work was supported by Metal Centre Čakovec under the project KK.01.1.1.02.0023.

Conflicts of Interest: The authors declare no conflict of interest. 


\section{References}

1. Dolgov, N.A.; Ts, D.; Dzh, D.; Pavlova, D.; Simov, M. Mechanical properties of dental CO-CR alloys fabricated via Casting and selective laser melting, Scientific Proceedings Ii International Scientific-Technical Conference "Innovations In Engineering". Mater. Sci. Non-Equilib. Phase Transform. 2016, 2, 3-7.

2. Țălu, Ş.; Stach, S.; Klaić, B.; Čelebić, A. Evaluation of Topographical Co-Cr-Mo Alloy Surface Changes After Various Finishing Treatments. Acta Stomatol. Croat. 2019, 53, 264-273. [CrossRef]

3. Han, X.; Sawada, T.; Schille, C.; Schweizer, E.; Scheideler, L.; Geis-Gerstorfer, J.; Spintzyk, S. Comparative Analysis of Mechanical Properties and Metal-Ceramic Bond Strength of Co-Cr Dental Alloy Fabricated by Different Manufacturing Processes. Materials 2018, 11, 1801. [CrossRef] [PubMed]

4. Gene'va, S. Dentistry-Metallic Materials for Fixed and Removable Restorations and Appliances; EN ISO 22674:2016; European Committee for Standardization: Brussels, Belgium, 2015.

5. Dikova, T. Properties of Co-Cr Dental Alloys Fabricated Using Additive Technologies. Biomater. Regen. Med. 2018, 141-159. [CrossRef]

6. Maltar, M.; Miloš, L.; Milardović, S.; Kovačić, I.; Peršić, S.; Juroš, I.; Kranjčić, J. Attitudes of the Students from the School of Dental Medicine in Zagreb towards CAD/CAM. Acta Stomatol. Croat. 2018, 52, 322-329. [CrossRef]

7. Attar, H.; Calin, M.; Zhang, L.C.; Scudino, S.; Eckert, J. Manufacture by selective laser melting and mechanical behavior of commercially pure titanium. Mater. Sci. Eng. A 2014, 593, 170-177. [CrossRef]

8. Zhou, Y.; Wei, W.; Yan, J.; Liu, W.; Li, N.; Li, H.; Xu, S. Microstructures and metal-ceramic bond properties of Co-Cr biomedical alloys fabricated by selective laser melting and casting. Mater. Sci. Eng. A 2019, 759, 594-602. [CrossRef]

9. Tasopoulos, T.; Kouveliotis, G.; Polyzois, G.; Karathanasi, V. Fabrication of a 3D Printing Definitive Obturator Prosthesis: A Clinical Report. Acta Stomatol. Croat. 2017, 51, 53-59. [CrossRef] [PubMed]

10. Dai, N.; Zhong, Y.; Liu, H.; Yuan, F.; Sun, Y. Digital modeling technology for full dental crown tooth preparation. Comput. Biol. Med. 2016, 71, 190-197. [CrossRef]

11. Liu, J.; Liu, Y.; Wang, J.; Zuo, X.; Wang, X.; Zhang, Y.; He, H. Dental measurements based on a three-dimensional digital technique: A comparative study on reliability and validity. Arch. Oral Biol. 2021, 124, 105059. [CrossRef]

12. Peng, M.; Li, C.; Huang, C.; Liang, S. Digital technologies to facilitate minimally invasive rehabilitation of a severely worn dentition: A dental technique. J. Prosthet. Dent. 2020, 126, 167-172. [CrossRef] [PubMed]

13. Yoon, S.; Jung, H.J.; Knowles, J.C.; Lee, H.H. Digital image correlation in dental materials and related research: A review. Dent. Mater. 2021, 37, 758-771. [CrossRef]

14. Torabi, K.; Farjood, E.; Hamedani, S. Rapid prototyping technologies and their applications in prosthodontics, Review of Literature. J. Dent. 2015, 16, 1-9.

15. Ucar, Y.; Akova, T.; Akyil, M.S.; Brantley, W.A. Internal fit evaluation of crowns prepared using a new dental crown fab-rication technique: Laser-sintered Co-Cr crowns. J. Prosthet. Dent. 2009, 102, 253-259. [CrossRef]

16. Tonelli, L.; Fortunato, A.; Ceschini, L. CoCr alloy processed by Selective Laser Melting (SLM): Effect of Laser Energy Density on microstructure, surface morphology, and hardness. J. Manuf. Process. 2020, 52, 106-119. [CrossRef]

17. Park, C.; Kee, W.; Lim, H.-P.; Park, S.-W. Combining 3D-printed metal and resin for digitally fabricated dentures: A dental technique. J. Prosthet. Dent. 2019, 123, 389-392. [CrossRef] [PubMed]

18. Di Fiore, A.; Meneghello, R.; Graiff, L.; Savio, G.; Vigolo, P.; Monaco, C.; Stellini, E. Full arch digital scanning systems performances for implant-supported fixed dental prostheses: A comparative study of 8 intraoral scanners. J. Prosthodont. Res. 2019, 63, 396-403. [CrossRef]

19. Leeson, D. The digital factory in both the modern dental lab and clinic. Dent. Mater. 2019, 36, 43-52. [CrossRef]

20. Viderščak, D.; Šolić, S.; Schauperl, Z.; Godec, M.; Ćatić, A.; Črtomir, D.; Paulin, I. The Influence of Machine Type on Microstructure and Mechanical Properties of 3D Printed Commercial Co-Cr Dental Alloy. In Proceedings of the Euro PM2020 Congress \& Exhibition/European Powder Metallurgy Association (EPMA), Lisbon, Portugal, 5-7 July 2020.

21. Koutsoukis, T.; Zinelis, S.; Eliades, G.; Al-Wazzan, K.; Rifaiy, M.A.; Al Jabbari, Y.S. Selective Laser Melting Technique of Co-Cr Dental Alloys: A Review of Structure and Properties and Comparative Analysis with Other Available Techniques. J. Prosthodont. 2015, 24, 303-312. [CrossRef] [PubMed]

22. Bellefontaine, G. The Corrosion of CoCrMo Alloys for Biomedical Applications. Ph.D. Thesis, School of Metallurgy and Materials, University of Birmingham, Birmingham, UK, January 2010.

23. Podrrez-Radziszewska, M.; Haimann, K.; Dudzinski, W.; Morawska-Soltysik, M. Characteristic of intermetallic phases in cast dental CoCrMo alloy. Arch. Foundry Eng. 2010, 10, 51-59.

24. Gupta, P. The Co-Cr-Mo (Cobalt-Chromium-Molybdenum) system. J. Phase Equilibria Diffus. 2005, 26, 87-92. [CrossRef]

25. Crook, P. Metals Handbook. Nonferrous Alloys and Special-Purpose Materials; Ohio American Society for Metals; ASM International: Materials Park, OH, USA, 1990; 447p.

26. Wang, J.-H.; Ren, J.; Liu, W.; Wu, X.-Y.; Gao, M.-X.; Bai, P.-K. Effect of Selective Laser Melting Process Parameters on Microstructure and Properties of Co-Cr Alloy. Materials 2018, 11, 1546. [CrossRef]

27. Takaichi, A.; Suyalatu, T.; Nakamoto, N.; Joko, N.; Nomura, Y.; Tsutsumi, S.; Migita, H.; Doi, S.; Kurosu, A.; Chiba, N.; et al. Microstructures and mechanical properties of $\mathrm{Co}-29 \mathrm{Cr}-6 \mathrm{Mo}$ alloy fabricated by selective laser melting process for dental applications. Mech. Behav. Biomed. Mater. 2013, 21, 67-76. [CrossRef] [PubMed] 
28. Al Jabbari, Y.S. Physico-mechanical properties and prosthodontic applications of Co-Cr dental alloys: A review of the literature. J. Adv. Prosthodont. 2014, 6, 138-145. [CrossRef]

29. Ni, J.; Ling, H.; Zhang, S.; Wang, Z.; Peng, Z.; Benyshek, C.; Zan, R.; Miri, A.K.; Li, Z.; Zhang, X.; et al. Three-Dimensional Printing of Metals for Biomedical Applications. Mater. Today Bio 2019, 3, 100024. [CrossRef]

30. Mergulhão, M.V.; Podestá, C.E.; das Neves, M.D.M. Perspective of Additive Manufacturing Selective Laser Melting in Co-Cr-Mo Alloy in the Consolidation of Dental Prosthesis. Biomater. Regen. Med. 2017, 161-185. [CrossRef]

31. Zhou, Y.; Li, N.; Yan, J.; Zeng, Q. Comparative analysis of the microstructures and mechanical properties of Co-Cr dental alloys fabricated by different methods. J. Prosthet. Dent. 2018, 120, 617-623. [CrossRef] [PubMed]

32. Chauhan, M. Microstructural Characterization of Cobalt Chromium (ASTM F75) Cubes Produced by EBM Technique. Master's Thesis, SE-412 96 Gothenburg, Chalmers University of Technology, Gothenburg, Sweden, 2017.

33. Konieczny, B.; Szczesio-Wlodarczyk, A.; Sokolowski, J.; Bociong, K. Challenges of Co-Cr Alloy Additive Manufacturing Methods in Dentistry-The Current State of Knowledge (Systematic Review). Materials 2020, 13, 3524. [CrossRef] [PubMed]

34. Donik, Č.; Kraner, J.; Paulin, I.; Godec, M. Influence of the Energy Density for Selective Laser Melting on the Microstructure and Mechanical Properties of Stainless Steel. Metals 2020, 10, 919. [CrossRef]

35. Øilo, M.; Nesse, H.; Lundberg, O.J.; Gjerdet, N.R. Mechanical properties of cobalt-chromium 3-unit fixed dental prostheses fabricated by casting, milling, and additive manufacturing. J. Prosthet. Dent. 2018, 120, 156.e1-156.e7. [CrossRef]

36. Yan, X.; Jiang, R.; Li, W.; Lin, H. Oriented face-centered cubic to hexagonal close-packed martensitic transition, grain morphology, and mechanical properties of Co-Cr alloy fabricated by selective laser melting. J. Prosthet. Dent. 2020. [CrossRef] [PubMed]

37. Kok, Y.; Tan, X.P.; Wang, P.; Nai, M.L.S.; Loh, N.H.; Liu, E.; Tor, S.B. Anisotropy and heterogeneity of mi-crostructure and mechanical properties in metal additive manufacturing: A critical review. Mater. Des. 2018, 139, 565-586. [CrossRef] 